\title{
Spatial and temporal variation of precipitation in Sudan and their possible causes during 1948-2005
}

\author{
Zengxin Zhang • Chong-Yu Xu • \\ Majduline El-Haj El-Tahir $\cdot$ Jianrong Cao • \\ V. P. Singh
}

Published online: 3 July 2011

(c) The Author(s) 2011. This article is published with open access at Springerlink.com

\begin{abstract}
Temporal and spatial patterns of precipitation are essential to the understanding of soil moisture status which is vital for vegetation regeneration in the arid ecosystems. The purposes of this study are (1) to understand the temporal and spatial variations of precipitation in Sudan during 1948-2005 by using high quality global precipitation data known as Precipitation REConstruction (PREC), which has been constructed at the National Oceanic and Atmospheric Administration (NOAA) Climate Prediction Center, and (2) to discuss the relationship between precipitation variability and moisture flux based on the NCEP/NCAR reanalysis data in order to ascertain the potential causes of the spatial and temporal variations of precipitation in the region. Results showed that (1) annual and monthly precipitation in Sudan had great spatial variability, and mean annual precipitation varied from almost nil in the North to about $1500 \mathrm{~mm}$ in the extreme
\end{abstract}

\section{Z. Zhang}

Jiangsu Key Laboratory of Forestry Ecological Engineering,

Nanjing Forestry University, Nanjing 210037, China

C.-Y. Xu $(\bowtie) \cdot$ M. E.-H. El-Tahir

Department of Geosciences, University of Oslo, P.O. Box 1047

Blindern, 0316 Oslo, Norway

e-mail: chongyu.xu@geo.uio.no

C.-Y. Xu

Department of Earth Sciences, Uppsala University,

Uppsala, Sweden

J. Cao

College of Environment and Planning, Liaocheng University, Liaocheng 251059, China

V. P. Singh

Department of Civil and Environmental Engineering, Texas A\&M University, College Station, TX 77843-2117, USA
Southwest; (2) precipitation of the main rain season, i.e., July, August and September, and annual total precipitation in the central part of Sudan decreased significantly during 1948-2005; (3) abrupt change points were found in the annual, July, August and September in the late 1960s, when precipitation decreased more rapidly than in other periods; and (4) the decreasing precipitation was associated with the weakening African summer monsoon. The summer moisture flux over Sudan tended to be decreasing after the late 1960s which decreased the northward propagation of moisture flux in North Africa. This study provides a complementary view to the previous studies that attempted to explain the Sahel persistent drought and possible causes.

Keywords Precipitation - Large scale $\cdot$ Abrupt .

Moisture flux · Sudan · African monsoon

\section{Introduction}

In recent years, droughts and subsequent famine and disease have devastated Africa and affected millions of people. With much of rural Africa already struggling to obtain adequate fresh water supplies, the drier conditions and altered precipitation patterns will make meeting the water needs of some of the poorest Africans much harder. Rainfall is the most important water resource in Sudan. However, low levels of rainfall have affected Sudan and resulted in severe droughts in recent years. The years 1983 and 1984 were the most difficult years for the region in recent history (Eltahir 1992). In 1984, crop failure and the spread of water-borne diseases caused by the drought took the lives of 55,000 people which weakened the socioeconomic capabilities of the nomadic tribes in Sudan (Osman and Shamseldin 2002). 
In Sudan, the rain-fed agriculture produces food for $90 \%$ of the population. Rainfall is caused by the southwesterly monsoon winds flowing from the Atlantic Ocean and the southeasterly monsoon winds flowing from the Indian Ocean (Osman and Shamseldin 2002). To ascertain the precipitation change and its possible cause in Sudan during the past decades, several observational studies, using meteorological data, point to the climate change in Sudan and these studies confirm that the temperature is rising and rainfall is declining for the past several decades which might accelerate environmental degradation and desertification in Sudan (e.g., Alvi 1994; Janowiak 1988; Nicholson et al. 2000). The precipitation anomaly of Sudan has been related to Sea Surface Temperature Anomalies (SSTAs) in the Gulf of Guinea (Lamb 1978a, b). Palmer (1986) has pointed out that the tropical Indian Ocean SST has a strong influence on the Sahel rainfall. Camberlin (1995) found that the dry and wet conditions over the Sahel were usually associated with warm conditions in the tropical Indian Ocean. Osman and Shamseldin (2002) also investigated the influence of El Niño-southern oscillation (ENSO) and the Indian Ocean Sea surface temperature (SST) on the rainfall variability in the central and southern regions of Sudan and found that the driest years were associated with warm ENSO and Indian Ocean SST conditions. Comprehensive analysis and reviews of rainfall trends and variability in Africa, including the Sahel region and Sudan had been carried out by Hulme and his coauthors (e.g., Trilsbach and Hulme 1984; Hulme 1987, 1990; Hulme and Tosdevin 1989; Walsh et al. 1988). Trilsbach and Hulme (1984) examined rainfall changes and their physical and human implications in the critical desertification zone between latitudes $12^{\circ} \mathrm{N}$ and $16^{\circ} \mathrm{N}$ of the Democratic Republic of Sudan and concluded, among others, that heavy falls of rain $(>40 \mathrm{~mm})$ are more likely to decline than medium $(>10 \mathrm{~mm})$ and light $(<10 \mathrm{~mm})$ falls. Walsh et al. (1988) reported that "rainfall decline in semiarid Sudan since 1965 has continued and intensified in the $1980 \mathrm{~s}$, with 1984 the driest year on record and all annual rainfalls from 1980 to 1987 well below the long-term mean". Hulme (1990) reported that rainfall depletion has been most severe in semi-arid central Sudan between 1921-1950 and 1956-1985. The length of the wet season has contracted, and rainfall zones have migrated southwards. A reduction in the frequency of rain events rather than a reduced rainfall yield per rain event was found to be the main reason for this depletion.

Increasingly the tendency has been for studies examining the causes of droughts, to look at global scales through the notion of teleconnections. It would seem reasonable that the current drought is a manifestation of an interaction of two or more mechanisms (Cook and Vizy 2006). Nicholson (1986) pointed out that the variations in the
Sahel rainfall are generally related to the changes in the intensity of the rainy season rather than to its onset or length as the ITCZ hypothesis would require.

Drought implies some form of moisture deficit and moisture plays an important role in understanding climate change (Prueger et al. 2004). Vertically integrated moisture flux and its convergence/divergence are closely related to precipitation. Much research work has been performed regarding the moisture flux over Africa (e.g., Cadet and Nnoli 1987; Fontaine et al. 2003; Osman and Hastenrath 1969). Cadet and Nnoli (1987) pointed out that the progressive penetration of moisture over West Africa during summer at $850 \mathrm{hPa}$ and the southerly flow penetrates up to $20^{\circ} \mathrm{N}$ during the maximum activity of the African monsoon. Hulme and Tosdevin (1989) assessed the relationship between tropical easterly jet (TEJ) and Sudan rainfall and found changes in the dynamics and flow of the TEJ exert some control over the Sahelian rainfall. Fontaine et al. (2003) analyzed the atmospheric water and moisture fluxes in West African Monsoon based on NCEP/NCAR and observed rainfall data and found that at more local scales moisture advections and convergences are also significantly associated with the observed Sudan-Sahel rainfall and in wet (dry) situations, with a clear dominance of westerly (easterly) anomalies in the moisture flux south of $15^{\circ} \mathrm{N}$.

Although many studies have attempted to explain the Sahel persistent drought in terms of general circulation features, sea surface temperatures, land surface feedback mechanisms, and teleconnected, spatiotemporal rainfall patterns. However, the cause of the Sahel drought remains elusive (Nicholson 1989; Rowell et al. 1995; Long et al. 2000; Trilsbach and Hulme 1984). Long et al. (2000) aimed to advance the understanding of these causes by examining rainfall, horizontal moisture transport, and vertical motion and how they differ regionally and seasonally. There are a few previous studies that have looked at how the precipitation variability is related to the moisture flux in Sudan. The main aim of this study is to provide a complementary view to the previous studies by examing the relationship of moisture flux and precipitation trend in the region. The specific objectives of the study are: (1) to understand the spatial and temporal variability of precipitation from Precipitation REConstructed (PREC) data in Sudan during 1948-2005; and (2) to investigate the relationship between precipitation and moisture flux in the region.

\section{Study area and data}

Sudan is a vast country with an area of about 2.5 million $\mathrm{km}^{2}$ and has an estimated population of about 41.1 million people. The climate ranges from arid in the north to tropical wet-and-dry in the far southwest. About two-thirds 
of Sudan lies in the dry and semi-dry region. Temperatures do not vary greatly with the season at any location; the most significant climatic variables are rainfall and the length of the rainy season. Except in the northeast region, from January to March, the country is under the influence of dry northeasterly winds, and during this period there is almost no rainfall countrywide except for a small area in north eastern Sudan where the winds pass over the Mediterranean bringing occasional light rains. By early April, rainy season starts from southern Sudan as the moist south westerlies reach the region, and by August the southwesterly flows extend to the northern limits. The dry northeasterlies begin to strengthen in September and to push south and cover the entire country by the end of December.

In this paper, we use the global monthly precipitation data (PREC) created by Chen et al. (2002) instead of NCEP/NCAR precipitation data, because previous studies have shown that the NCEP/NCAR reanalysis precipitation exhibits some deficiencies and that this field does not compare as well with observations as other reanalysis fields, such as heights, winds, and temperatures that are assimilated directly into the model (Poccard et al. 2000; Janowiak et al. 1998). Monthly precipitation data have been selected from the global precipitation reconstruction data (PREC) estimates on a $0.5 \times 0.5^{\circ}$ latitude/longitude grid over the period 1948-2005 in Sudan, which has in total 890 grids. The PREC analyses are derived from gauge observations from over 17,000 stations collected in the Global Historical Climatology Network (GHCN), version 2, and the Climate Anomaly Monitoring System (CAMS) datasets. The global analyses are defined by interpolation of gauge observations over land (PREC/L) and by using empirical orthogonal functions (EOF) for interpolation and subsequent reconstruction of historical observations over ocean (PREC/O) (Chen et al. 2002). Shi et al. (2002a, b, 2004) analyzed the global land precipitation dataset (PREC/L) and found that this dataset was accurate enough for describing the change of large scale precipitation, and there was a good relationship between the global precipitation database (PREC) and observed Western Africa monsoon precipitation during 1948-2001. In the Northern Hemisphere, the tropical area to the south of $25^{\circ} \mathrm{N}$, precipitation showed a negative trend in all seasons. For comparison, long-term mean monthly precipitation dataset from 39 observed rain gauge stations from GHCH Version 2 were also used in this study. The location of Sudan and observed and reconstructed grid points can be referred to Fig. 1 and Table 1. Figure 1 shows that the PREC data has, in general, a good agreement with observed data. In the rest of the paper detailed analysis is only done for the PREC data, because the observed data has too few stations and only 12 long-term mean monthly values are available.
Atmospheric data from NCEP/NCAR-I reanalysis (R-1) over the period 1948-2005 are available on a $2.5 \times 2.5^{\circ}$ latitude/longitude grid. The water vapor flux of the whole Ps layer (surface pressure) $-300 \mathrm{hPa}$ was analyzed in this study. In the actual atmosphere, the moisture is very low over $300 \mathrm{hPa}$, so $p=300 \mathrm{hPa}$ will be used in the calculation.

\section{Methods}

The Mann-Kendall trend test (MK; Mann 1945; WMO 1966; Kendall 1975; Sneyers 1990) is widely used in the literature to analyze trends in the climate data. The MK test has different variants. In this study two different versions are used for two different purposes. The procedure of the first version as demonstrated by Zhang et al. (2010a) starts by simply comparing the most recent data with earlier values. A score of +1 is awarded if the most recent value is larger, or a score of -1 is awarded if it is smaller. The total score for the time-series data is the Mann-Kendall statistic, $Z$, which is then compared to a critical value, $Z_{1-\alpha / 2}$ (where $\alpha$ is significance level, and $Z_{1-\alpha / 2}$ is the $Z$ value found in the standard normal distribution table), to test whether the trend in the data is significantly increasing $\left(Z>Z_{1-\alpha / 2}\right)$, significantly decreasing $\left(Z<-Z_{1-\alpha / 2}\right)$ or if no trend $\left(-Z_{1-\alpha / 2}<Z<Z_{1-\alpha / 2}\right)$. This procedure is used to produce results as showed in Figs. 4 and 7, and in Table 2.

In contrast to the traditional MK test which calculates above statistic variables only once for the whole sample, MK method can also be used to test an assumption regarding the beginning of the development of a trend within a sample, i.e., a changing point in the time series (Zhang et al. 2009). Following the procedure as shown by Gerstengarbe and Werner (1999) who used the method to test an assumption about the beginning of the development of trend within a sample $(x 1, x 2, \ldots, x \mathrm{n})$ of the random variable $X$, the corresponding rank series for the so-called retrograde rows are similarly obtained for the retrograde sample $\left(x_{\mathrm{n}}, x_{\mathrm{n}-1}, \ldots, x 1\right)$. Based on the rank series $\mathrm{r}$ of the progressive and retrograde rows of this sample, the statistic variables, $Z_{1}$ and $Z_{2}$ will be calculated for the progressive and retrograde samples, respectively. The $Z_{1}$ and $Z_{2}$ values calculated with progressive and retrograde series are named UF and UB, respectively, in this paper. The intersection point of the two lines, UF and UB gives the point in time of the beginning of a developing trend within the time series. This method is used to produce results as showed in Fig. 5b.

As a complementary method of trend analysis, simple linear regression was also used in this paper for long-term linear trend test. The simple linear regression method is a parametric $T$-test method, which consists of two steps, fitting a linear simple regression equation with the time $t$ as independent variable and the hydrological variable (i.e. 


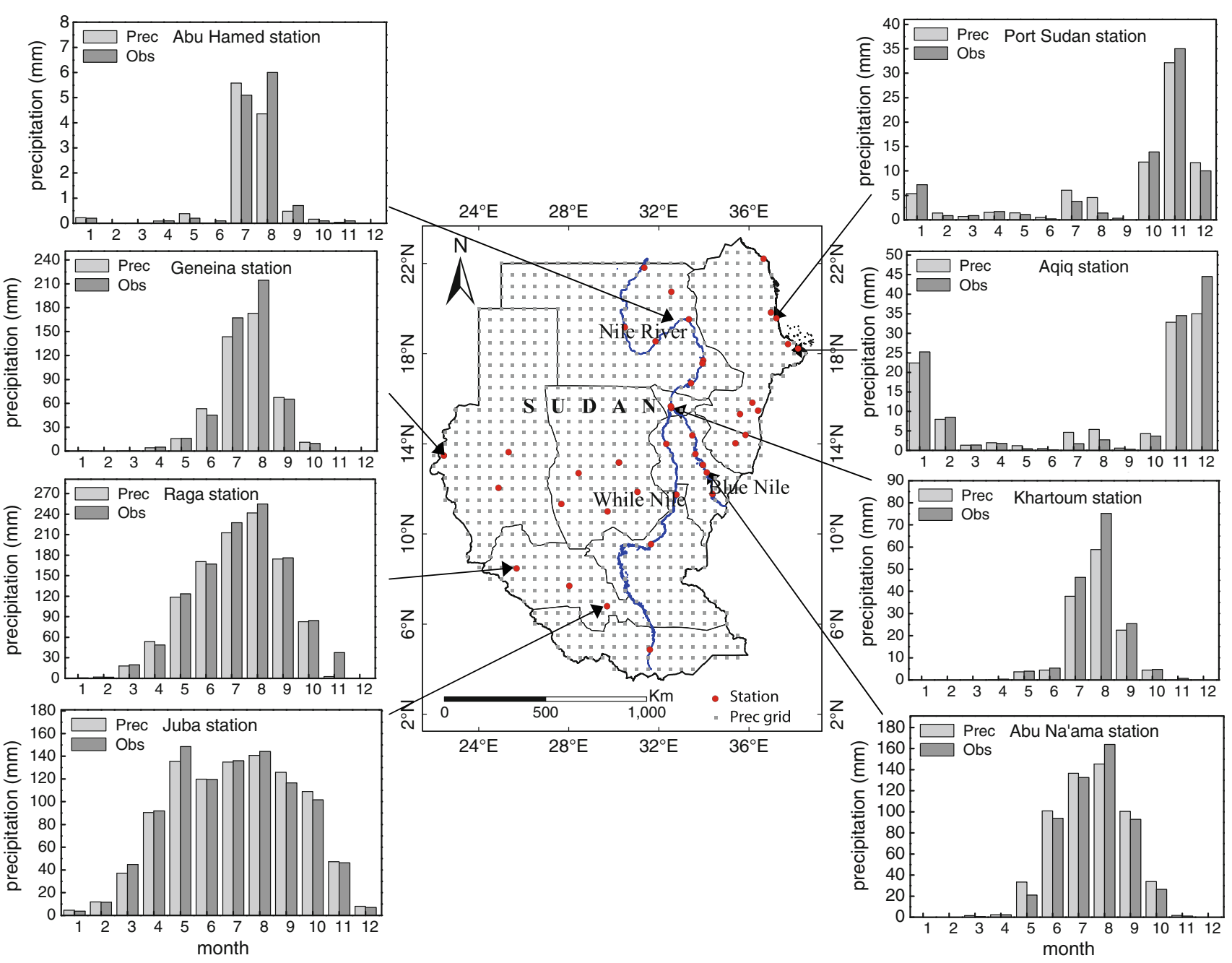

Fig. 1 Sketch map of the observed rain gauge station (Obs) and selected precipitation grid point "station" based on Precipitation REConstruction (PREC) in Sudan (the bar graph are the seasonal

precipitation and moisture flux in this study) $Y$ as dependent variable; testing the statistical significance of the slope of the regression equation by the $t$-test (Xu 2001; Zhang et al. 2010a). The parametric $T$-test requires the data to be tested is normally distributed. The normality of the data series is first tested in the study by applying the Kolmogorov-Smirnov test. The $T$-test method is used to produce the results as showed in Figs. 5a and 9.

It is evident that the power of the test to detect the existing trend is significantly influenced by, among others, serial correlation in the time series and sample size or record length. The larger the sample size, the more powerful the test. Therefore, the assessment results of time series with different record length should not be put together to infer a general trend tendency (Yue and Wang 2002a, b). In this study, the data length of rainfall for all the grid points is 58 years (1948-2005). In this study, the influence of serial correlation in the time series on the mean observed and reconstruction precipitation for selected representative stations)

results of MK test was eliminated by prewhitening (e.g., Yue et al. 2002; Yue and Wang 2002a, b). "Prewhitening" is one of the methods used to prevent false indication of trend, where autocorrelation is removed from the data by assuming a certain correlation model, usually a Markovian one (e.g., Von Storch 1995).

The zonal moisture transport flux $\left(Q_{U}\right)$ and meridional moisture transport flux $\left(Q_{V}\right)$ were calculated based on the following equations (Cadet and Nnoli 1987; Zhou et al. 1998):

$$
\begin{aligned}
& Q_{u}(x, y, t)=\frac{1}{g} \int_{p_{\mathrm{s}}}^{p} q(x, y, p, t) u(x, y, p, t) \mathrm{d} p \\
& Q_{v}(x, y, t)=\frac{1}{g} \int_{p_{\mathrm{s}}}^{p} q(x, y, p, t) v(x, y, p, t) \mathrm{d} p
\end{aligned}
$$


Table 1 List of rain gauge stations used in this study in Sudan

\begin{tabular}{|c|c|c|c|c|c|c|}
\hline \multirow[t]{2}{*}{$\begin{array}{l}\text { Station } \\
\text { No. }\end{array}$} & \multirow[t]{2}{*}{ Name } & \multicolumn{2}{|c|}{$\begin{array}{l}\text { Latitude } \\
\text { (N) }\end{array}$} & \multicolumn{2}{|c|}{$\begin{array}{l}\text { Longitude } \\
\text { (E) }\end{array}$} & \multirow{2}{*}{$\begin{array}{l}\text { Annual } \\
\text { mean } \\
\text { precipitation } \\
(\mathrm{mm})\end{array}$} \\
\hline & & Deg. & Min. & Deg. & Min. & \\
\hline 62600 & Wadi Halfa & 21 & 49 & 31 & 21 & 0.6 \\
\hline 62615 & Halaib & 22 & 13 & 36 & 39 & 27.8 \\
\hline 62620 & Station No. 6 & 20 & 45 & 32 & 33 & 5.9 \\
\hline 62635 & Arbaat & 19 & 50 & 36 & 58 & 35.6 \\
\hline 62640 & Abu Hamed & 19 & 32 & 33 & 20 & 12.6 \\
\hline 62641 & Port Sudan & 19 & 35 & 37 & 13 & 76.1 \\
\hline 62650 & Dongola & 19 & 10 & 30 & 29 & 12.3 \\
\hline 62660 & Karima & 18 & 33 & 31 & 51 & 20.7 \\
\hline 62675 & Aqiq & 18 & 14 & 38 & 11 & 124.9 \\
\hline 62680 & Atbara & 17 & 42 & 33 & 58 & 59.9 \\
\hline 62682 & Hudeiba & 17 & 34 & 33 & 56 & 39.4 \\
\hline 62700 & Shendi & 16 & 42 & 33 & 26 & 77.6 \\
\hline 62721 & Khartoum & 15 & 36 & 32 & 33 & 162.4 \\
\hline 62722 & Aroma & 15 & 50 & 36 & 9 & 193.6 \\
\hline 62723 & Shambat Obs. & 15 & 40 & 32 & 32 & 127.5 \\
\hline 62730 & Kassala & 15 & 28 & 36 & 24 & 251.2 \\
\hline 62733 & $\begin{array}{r}\text { Halfa El } \\
\text { Gedida }\end{array}$ & 15 & 19 & 35 & 36 & 238.3 \\
\hline 62735 & Showak & 14 & 24 & 35 & 51 & 501.9 \\
\hline 62750 & Ed Dueim & 14 & 0 & 32 & 20 & 274 \\
\hline 62751 & Wad Medani & 14 & 23 & 33 & 29 & 306.4 \\
\hline 62752 & Gedaref & 14 & 2 & 35 & 24 & 603 \\
\hline 62760 & El Fasher & 13 & 38 & 25 & 20 & 212.6 \\
\hline 62762 & Sennar & 13 & 33 & 33 & 37 & 410.1 \\
\hline 62770 & Geneina & 13 & 29 & 22 & 27 & 523.8 \\
\hline 62771 & El Obeid & 13 & 10 & 30 & 14 & 318.1 \\
\hline 62772 & Kosti & 13 & 10 & 30 & 14 & 351.1 \\
\hline 62781 & En Nahud & 12 & 42 & 28 & 26 & 335.9 \\
\hline 62790 & Nyala & 12 & 3 & 24 & 53 & 398.3 \\
\hline 62795 & Abu Na'ama & 12 & 44 & 34 & 8 & 556 \\
\hline 62801 & Renk & 11 & 45 & 32 & 47 & 475.2 \\
\hline 62803 & Rashad & 11 & 52 & 31 & 3 & 717.7 \\
\hline 62805 & Damazine & 11 & 47 & 34 & 23 & 712.9 \\
\hline 62809 & Babanusa & 11 & 20 & 27 & 40 & 497.3 \\
\hline 62810 & Kadugli & 11 & 0 & 29 & 43 & 633.1 \\
\hline 62840 & Malakal & 9 & 33 & 31 & 39 & 731.6 \\
\hline 62871 & Raga & 8 & 28 & 25 & 41 & 1141.6 \\
\hline 62880 & Wau & 7 & 42 & 28 & 1 & 1074.5 \\
\hline 62900 & Rumbek & 6 & 48 & 29 & 42 & 847.7 \\
\hline 62941 & Juba & 4 & 52 & 31 & 36 & 972.7 \\
\hline
\end{tabular}

where $u$ and $v$ are the zonal and meridional components of the wind field, respectively; $q$ is the specific humidity; $p_{\mathrm{s}}$ is the surface pressure; $p$ is atmospheric top pressure; and $g$ is the acceleration of the gravity (e.g., Cadet and Nnoli 1987; Miao et al. 2005; Zhang et al. 2010b).

\section{Results}

\subsection{Characteristics of annual precipitation}

Before spatial and temporal variabilities of the annual precipitation data of PREC are examined, the standardized PREC data and the Sahel precipitation index are compared first. Results of comparison, shown in Fig. 2 for the Sahel area $\left(10-20^{\circ} \mathrm{N}, 20^{\circ} \mathrm{W}-10^{\circ} \mathrm{E}\right)$, reveal that the PREC data has a good agreement with the Sahel precipitation index in the study region. Spatial distributions of mean annual precipitation revealed by the PREC data are then compared with the interpolated observed data of 39 stations for the period 1961-1990 and the comparison is shown in Fig. 3. It can be seen from this figure that the average annual precipitation varies greatly in Sudan and it varies from almost nil in the north to more than $1000 \mathrm{~mm}$ in the Southwest. From the spatial angle, the distribution shows that rainfall is decreasing from south to north. The two-third of the whole country is controlled by arid and semiarid climate with annual precipitation of less than $600 \mathrm{~mm}$. The observed average annual precipitation between 1961 and 1990 also shows similar spatial patterns in Sudan (Fig. 3b). In general there is a good agreement between the two data sets. However, due to the limited number of stations some details of the spatial variability of mean annual precipitation as revealed in Fig. 3a are lost in b, especially in the rainfall rich region of South Sudan. Figure 3c estimates the magnitude and percentage of overestimations of PREC precipitation compared to the observed precipitation which provides important information for engineering designs. The results show that PREC precipitation are higher than observed precipitation, the amount of differences increases from north to south, however, the percentage of the increases is approximately $10 \%$ in the whole Sudan, except in the southeast which PREC is $17 \%$ higher than the observed values.

The trend analysis showed that the annual precipitation decreased in Sudan during 1948-2005 and the significant decreasing trend was found in central Sudan (Fig. 4). When the annual average precipitation over the whole country is concerned, a significant decreasing trend also exists during 1948-2005 (Fig. 5a). Furthermore, a study of year to year changes in the areal average annual precipitation by using the rank-based Mann-Kendall method (Gerstengarbe and Werner 1999) showed that a change point was found in around 1969 in the process (Fig. 5b). Similar results were obtained by Hulme (1990) when he reported that the depletion has been most severe in semi-arid Central Sudan. Other researchers, e.g., Osman and Shamseldin (2002), also found that the areal annual averaged rainfall values decreased markedly since the 1960s, and the drought in 1970s produces a large number of impacts that affects 
Table 2 Trends and abrupt point of areal average monthly and annual precipitation by MK method during 1948-2005 in Sudan

\begin{tabular}{|c|c|c|c|c|c|c|c|c|c|c|}
\hline Month & Mar & Apr & May & Jun & Jul & Aug & Sep & Oct & Nov & Annual \\
\hline MK value & -0.15 & -0.01 & -0.66 & -1.15 & $-2.03^{\mathrm{a}}$ & $-3.44^{\mathrm{a}}$ & $-2.28^{\mathrm{a}}$ & 0.26 & 0.61 & -3.38 \\
\hline Abrupt change point & - & - & - & - & 1968 & 1967 & 1970 & - & - & 1968 \\
\hline
\end{tabular}

a Statistically significant trends at the 0.05 levels, - None abrupt change point

Sudan's social, environmental, and economical standard of living with reduced crop, reduced water levels, increased livestock and wildlife death rates and damage to wildlife and fish habitat.

\subsection{Monthly precipitation during the rainy season}

As mentioned above, from January to March, Sudan is under the influence of dry north-easterlies. There is practically no rainfall countrywide except for a small area in northeastern Sudan (Fig. 1). The length of the rainy season decreases from about 9 months in the south to as little as 3 months on the southern fringes of the desert in the north, as revealed by Fig. 1. This study defines the rainy season in Sudan as the period between March and November.

The spatial distribution of average monthly precipitation for the period 1948-2005 in the rainy season is shown in Fig. 6. It is seen that regional scale precipitation starts in March and April, when the rainy season monsoons hit the southwestern area. In March, the moist southwesterlies reach southern Sudan bringing precipitation of an average magnitude of $70 \mathrm{~mm}$ to southern areas (Fig. 6a). In May, rains blow northwards, and southern Sudan gets more rainfall (Fig. 6c). By August, the rain belt extends to its usual northern limits and the precipitation amount reaches the maximum, causing southwest and southeast areas to receive an average of $280 \mathrm{~mm}$ of precipitation in a month (Fig. 6f). The rainy season in North Sudan onsets in June and extends to July, August and September, ending eventually in October, and in November the monsoons retreat gradually from the country.

The temporal trends of the selected monthly precipitation in the rainy season and the annual totals are analyzed by using the MK test method (Table 2). The $Z$ values indicate that significant decreasing trends exist in the main rainy months (July, August and September) with the steepest decrease found in August which is also the month receiving the maximum amount of rainfall in the country. Trilsbach and Hulme (1984) also reported that heavy rains in the rain season declined more did than median and light rains. Table 2 also shows that decreasing trends exist in most months except October and November; consequently, the areal average annual precipitation is also decreasing significantly. The change point was found between 1967 and 1970 for the rainy season months. Previous studies have also noted

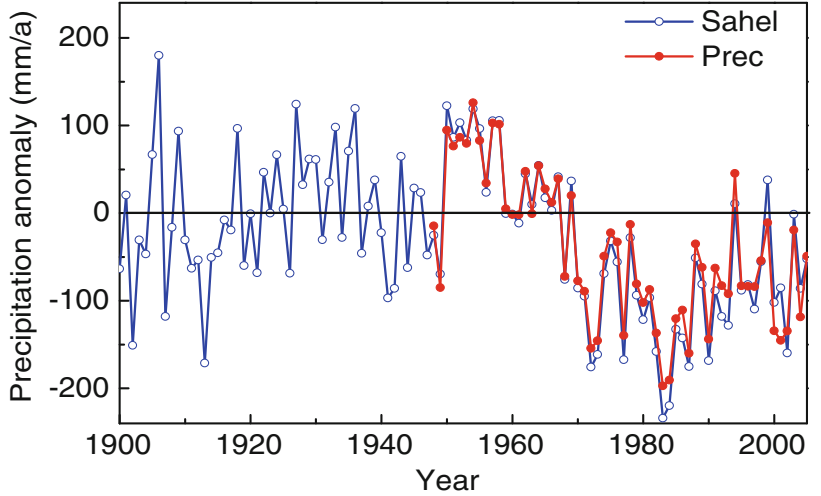

Fig. 2 Average annual areal precipitation anomaly in Sahel area $\left(10-20^{\circ} \mathrm{N}, 20^{\circ} \mathrm{W}-10^{\circ} \mathrm{E}\right)$. The line with hollow circle is based on the Sahel precipitation index, data are available at ftp://nomad3.ncep. noaa.gov/pub/sst/monthly; while the line with solid circle comes from the Precipitation REConstruction (PREC) data

that summer precipitation in the sub-Saharan region and Northeast China showed significant decreases around the year 1968, and precipitation over the Sahel region decreased sharply since then with drought persisting throughout the 1970s and 1980s (Lamb 1982, 1983; Quan et al. 2003).

For illustrative purposes, spatial variations of the MK trend for May-October are shown in Fig. 7. It is seen that in May an increasing trend in monthly rainfall is found in north Sudan while an insignificant decreasing trend occurs in most part of Sudan. In June and July, the country is dominated by a decreasing trend in monthly rainfall, but this trend is mostly insignificant except in one or two small regions which were marked as shadow areas. In August, however, a large part of central Sudan is dominated by significant deceasing trends, and in September a similar pattern as in July is found. There exists no significant temporal changing trend in October in Sudan except in the north-eastern corner where a significant increasing trend is found. From this picture, we can find that the rainfall decreases in the central Sudan during the rainy season.

\subsection{Transition of precipitation and moisture flux anomalies}

Sudan's climate ranges from tropical to continental, while most parts of southern Sudan experience a monsoon 


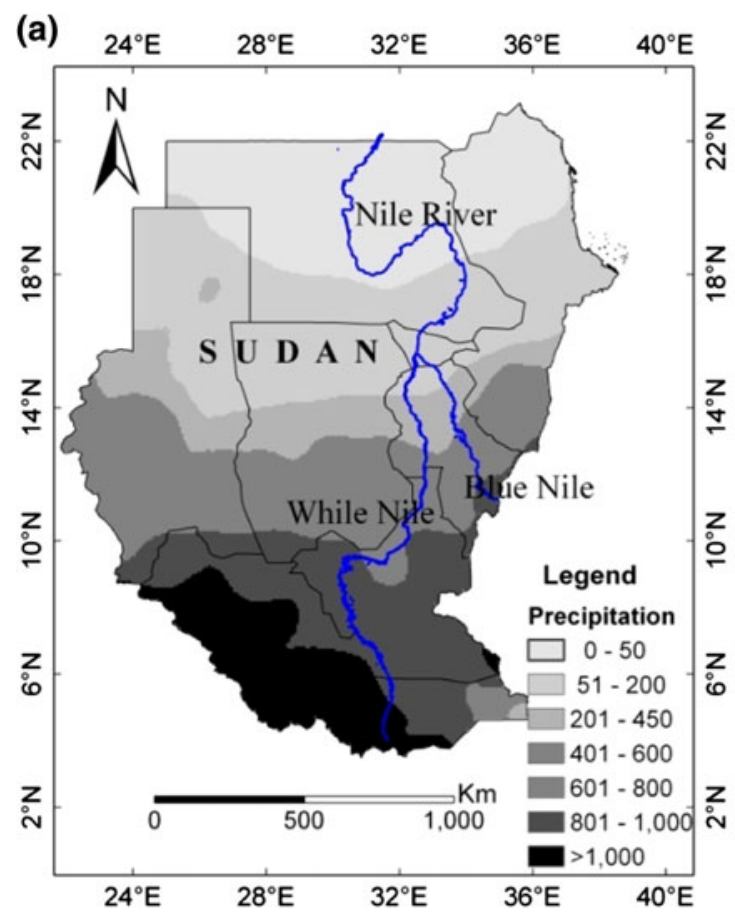

(b)
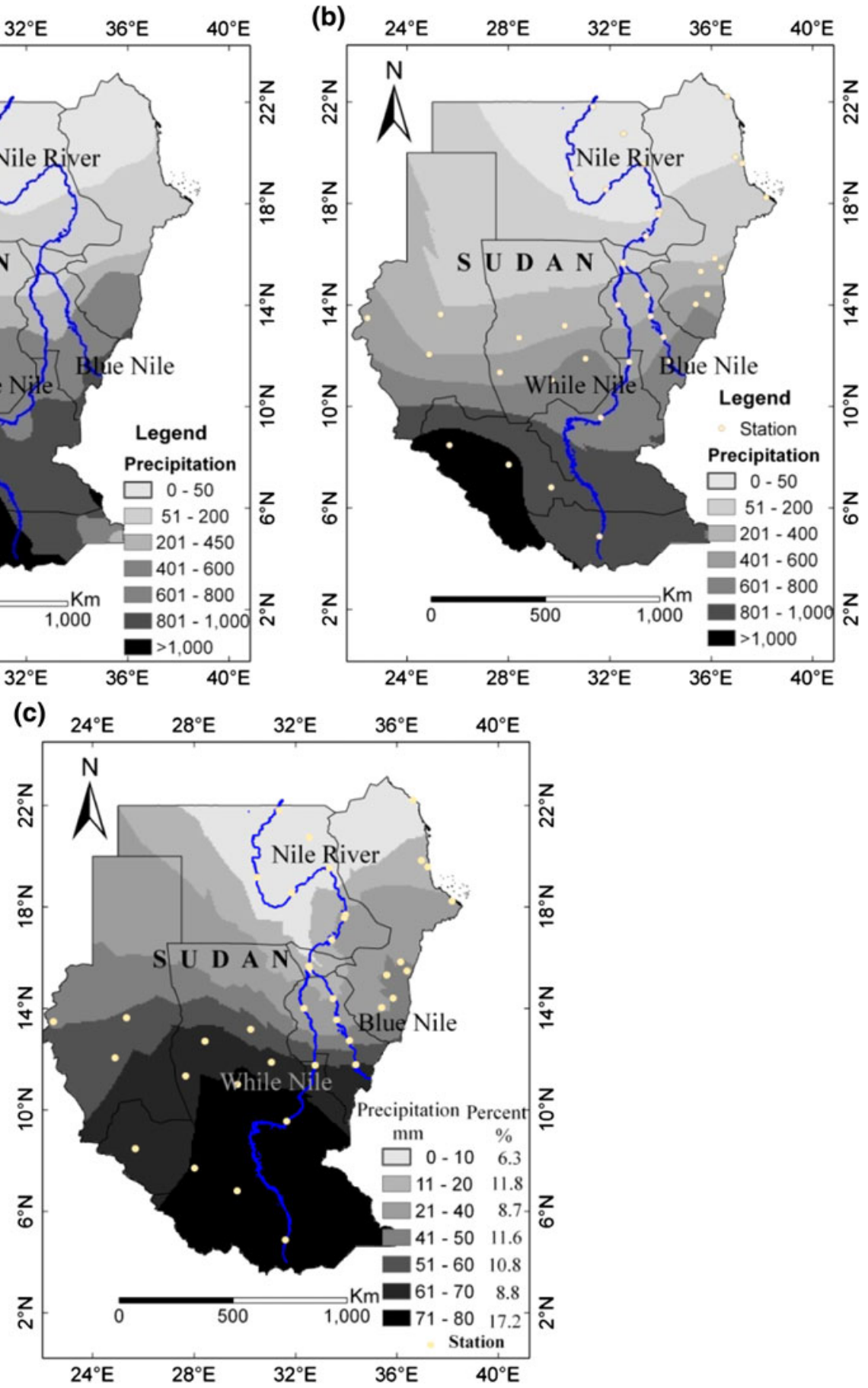

Fig. 3 The average of annual mean precipitation based on Precipitation REConstruction (PREC) (a), observed precipitation data (b) during 1961-1990, and PREC minus the observed precipitation (c) in Sudan The dots in b and $\mathbf{c}$ stand for observation stations

climate. The amounts of precipitation and the length of rainy season depend on which of the following two air flows predominates: the dry northeasterly winds from the Arabian Peninsula or moist southwesterly winds from the Congo River basin. In the rainy season, the moist southwesterlies reach southern Sudan and bring more precipitation. By July the moist air will reach Khartoum, Sudan's capital located in the central part, and in August it extends to its usual northern limits around Abu Hamad in the northern part. The flow becomes weaker as it spreads north. In September the dry northeasterlies begin to strengthen and to push south and by the end of December they cover the entire country.

It is therefore important to study the relationship between the African monsoon and the precipitation of Sudan and investigate how the changes in the African 


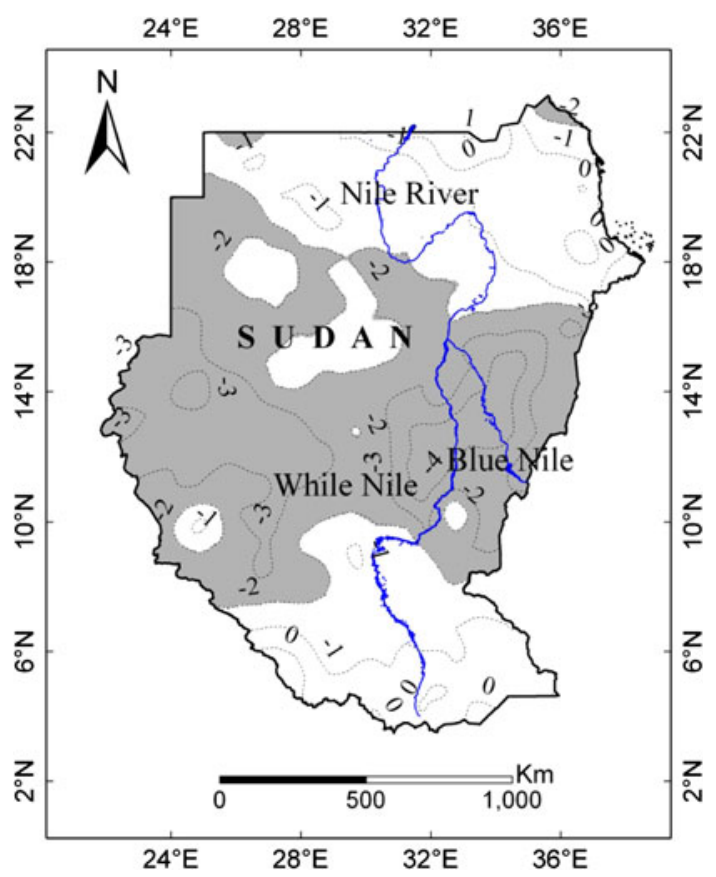

Fig. 4 The MK trends in annual precipitation in Sudan. The values of contour lines depict the test statistics $Z$ values of MK test. Solid lines indicate increasing regions and dashed lines indicate decreasing regions, and gray regions indicate the trend is statistically significant at the $5 \%$ significance level

monsoon have influenced the amount of precipitation during the rainy season. It is also desirable to explore how the African monsoon has changed and whether this change is one of the main causes for the rainfall decrease and the abrupt change in annual and monthly precipitation found around 1968. Therefore, we analyzed the variability of atmospheric moisture content and moisture flux in the past decades and the average moisture flux anomalies to explain the transition of precipitation in Sudan. From Fig. 8, it is found that the whole layer of moisture content significantly has decreased in central Sudan in summer since the late 1960s which might be related to the decline in precipitation in central Sudan. The spatial distribution of temporal linear trend of the atmospheric moisture flux in 1948-2005 in Africa is shown in Fig. 9. It can be seen that the whole layer of moisture flux in summer (JJA) during 1948-2005 decreased significantly in the central part of Africa including Sudan. The significant negative trends of zonal and meridional moisture flux found in Sudan indicated that there was a weak western and southern moisture flux, respectively. Figure 10 shows the spatial distribution of summer moisture flux anomalies during 1970-2005, when compared to that during 1948-1969. It is seen that there was an obvious northeastern moisture flux in Sudan. The northeasterly wind tendency in Sudan indicated that there was a weak summer monsoon since the late 1960s, and the weak summer monsoon limited the northward propagation
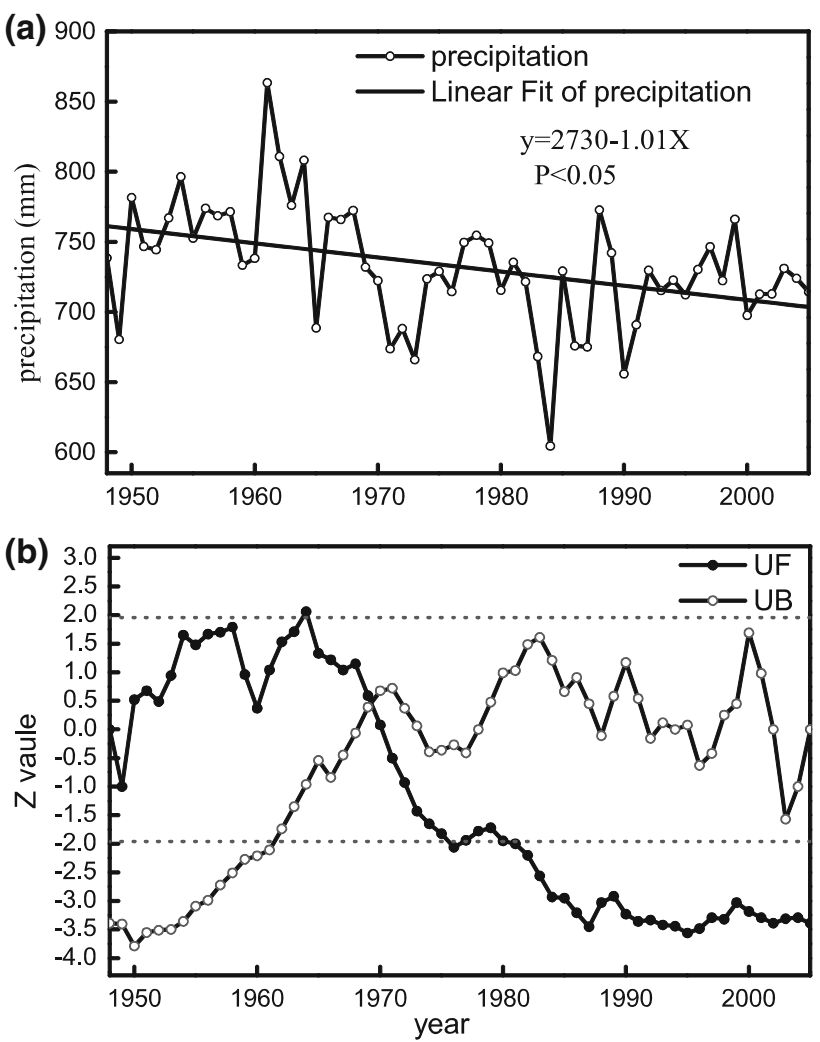

Fig. 5 a The linear trend of areal average annual precipitation in Sudan ( $P$-values show the significance level and when the $P$-value is smaller than 0.05 meaning that the trend is statistically significant at $5 \%$ significance level); b the turning point detected by using MK method. The time series has a downward trend if $U F<0$ and an increasing trend if $U F>0$. If the $U F$ value is greater than the critical values (the two dashed lines), then this upward or downward trend is significant at $5 \%$ significance level. When the $U F$ and $U B$ curves intersect at a certain time, the intersection point denotes the jumping time

of moisture to North Sudan. As a result, precipitation decreases significantly, especially in central Sudan. This observation is in line with changes in precipitation in Sudan, showing a close agreement between moisture flux alterations and changes in precipitation. The changes in African monsoon in the late 1960s make the circulation and precipitation change. The decades of the 1970s and 1980s saw the southwesterlies frequently fail, with disastrous results for the Sudanese people and economy.

\section{Discussions}

The decrease in precipitation in rainy season has led to more severe and longer-lasting droughts in Sudan. Increasing drought frequency has the potential to affect land-based natural and managed ecosystems, coastal systems, and both freshwater quality and quantity (Alvi 1994; Janowiak 1988; Nicholson et al. 2000). The current study 


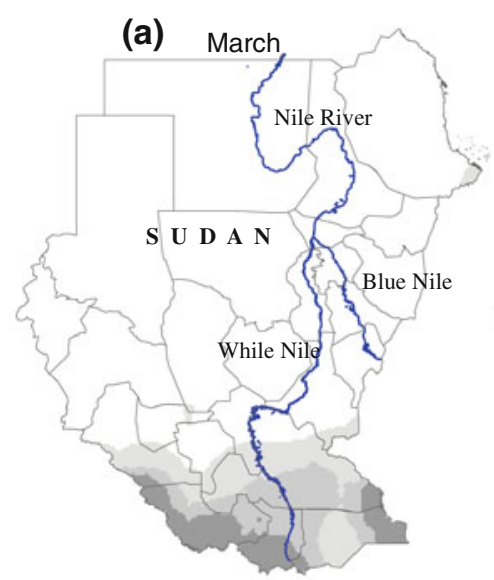

(d)
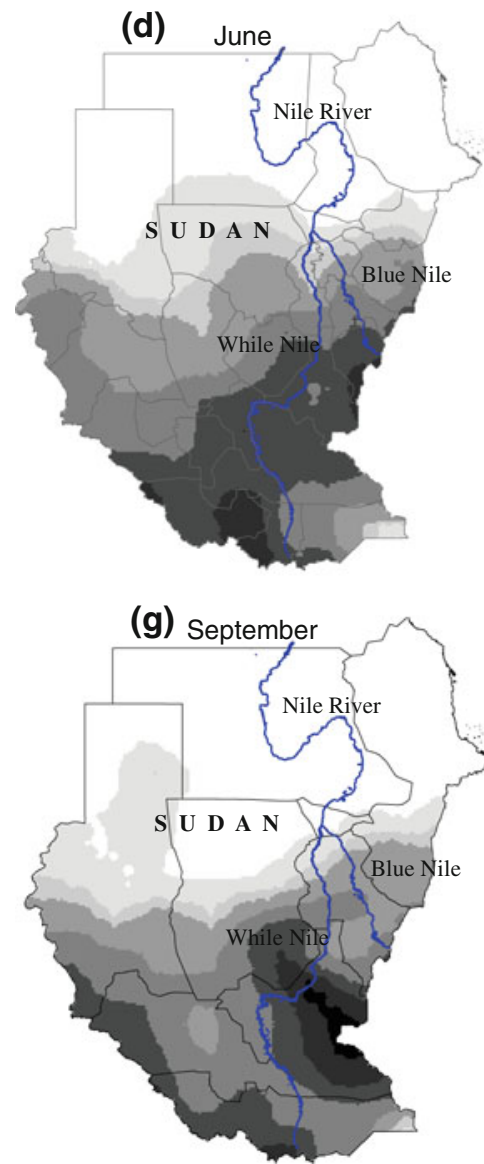
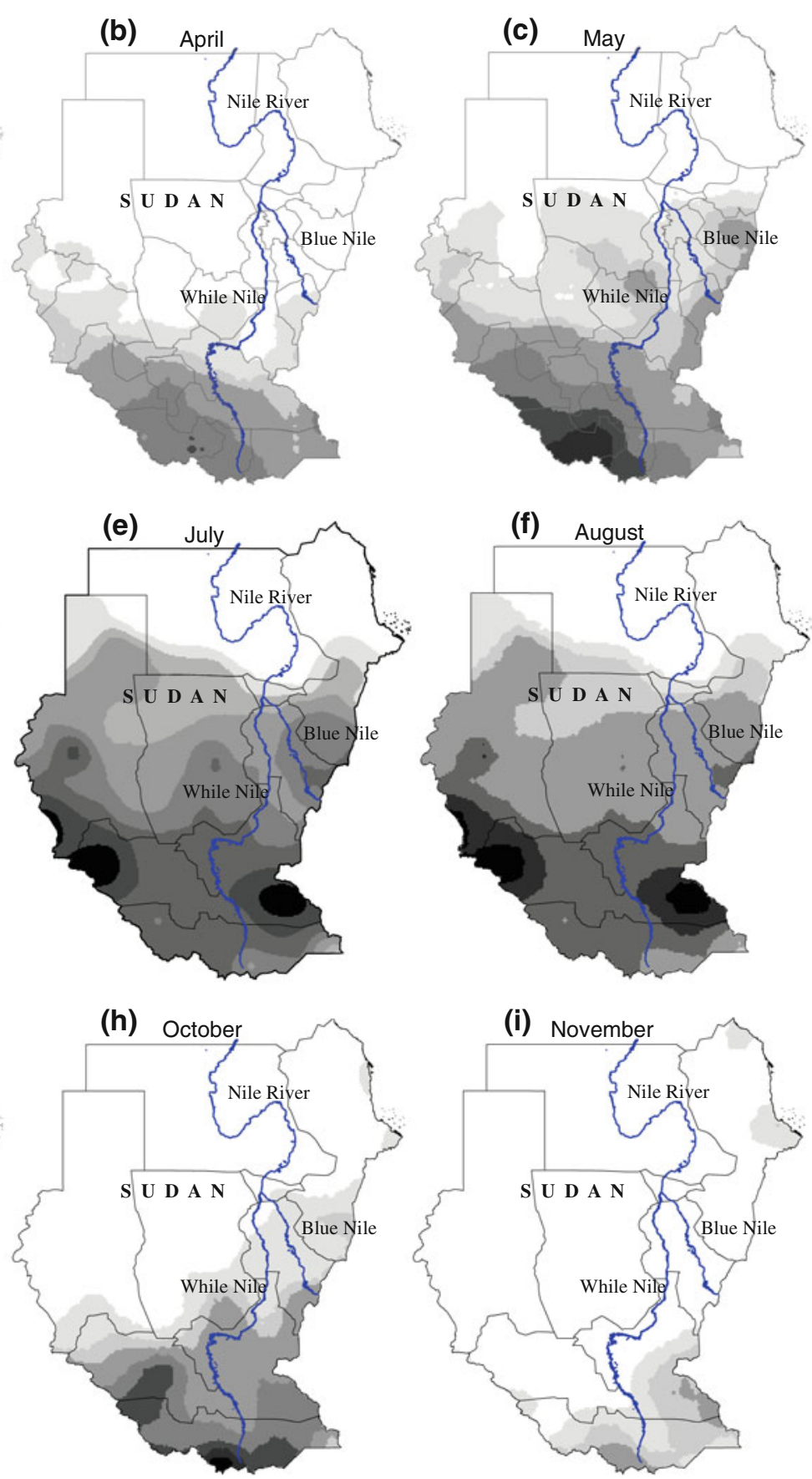

$\mathrm{mm}$
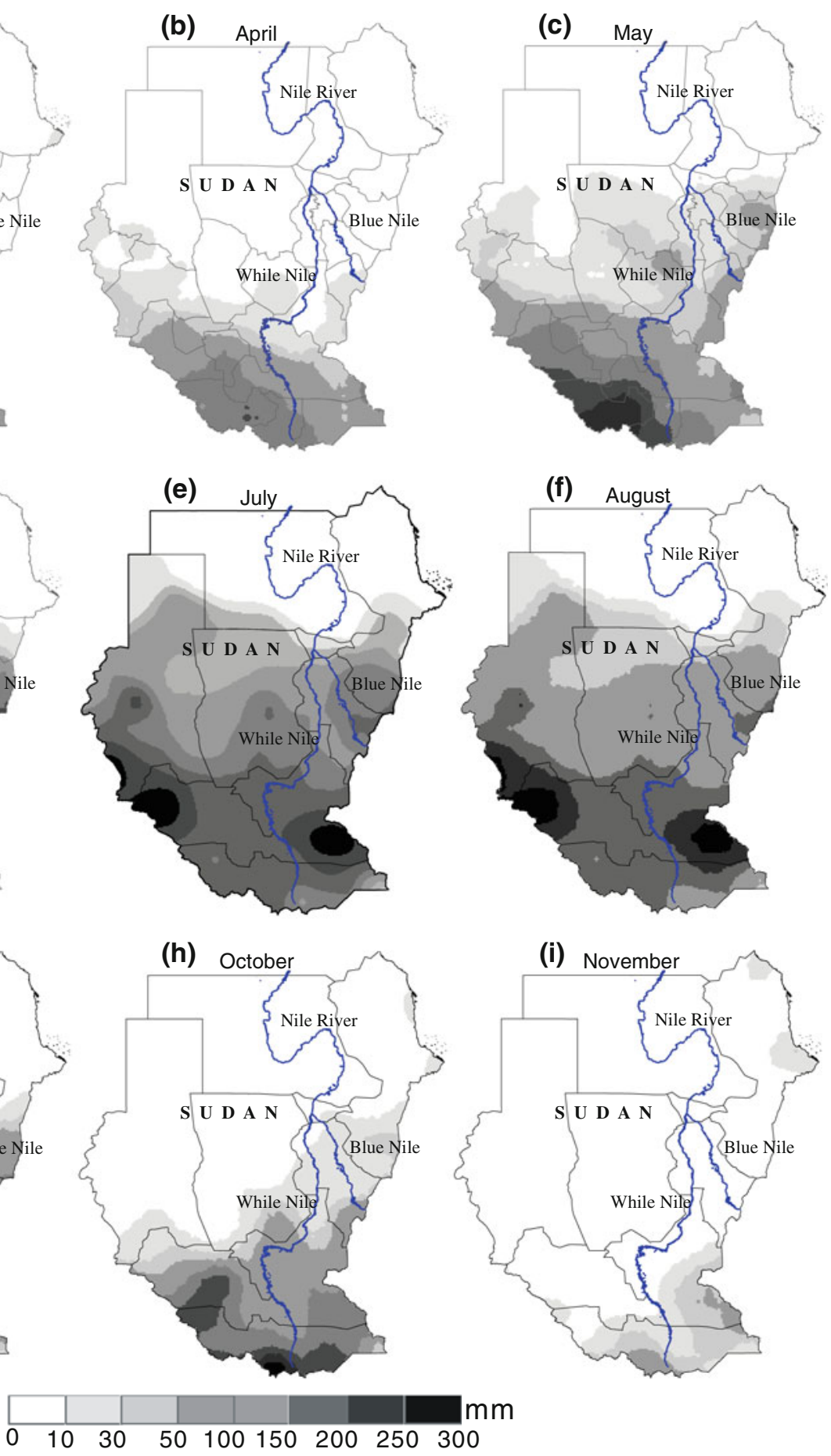

Fig. 6 The monthly average precipitation in rainy season in Sudan averaged over the period 1948-2005

reveals the annual and monthly changing characteristics of precipitation during 1948-2005 in Sudan. The annual precipitation has a significant decreasing trend in central Sudan, which is particularly caused by the decrease in the amount of rains in July, August and September. The decreasing trend in precipitation in Sudan, particularly after mid-1960s, is in agreement with regional precipitation changes as reported in earlier studies. For example, Eltahir (1988) and Long et al. (2000) found the annual rainfall amounts in the entire region of central and western Africa decreased since the late 1960s. The mechanisms of droughts in Sudan are complex and many studies have been made to examine the causes of droughts. However, the cause of the Sahel drought remains elusive (Nicholson 
Fig. 7 Spatial distribution of the MK trend for the selected months. The values of contour lines depict the test statistics $Z$ values of MK test. Solid lines indicate increasing regions and dashed lines indicate decreasing regions, and gray regions indicate the trend is statistically significant at the $5 \%$ significance level
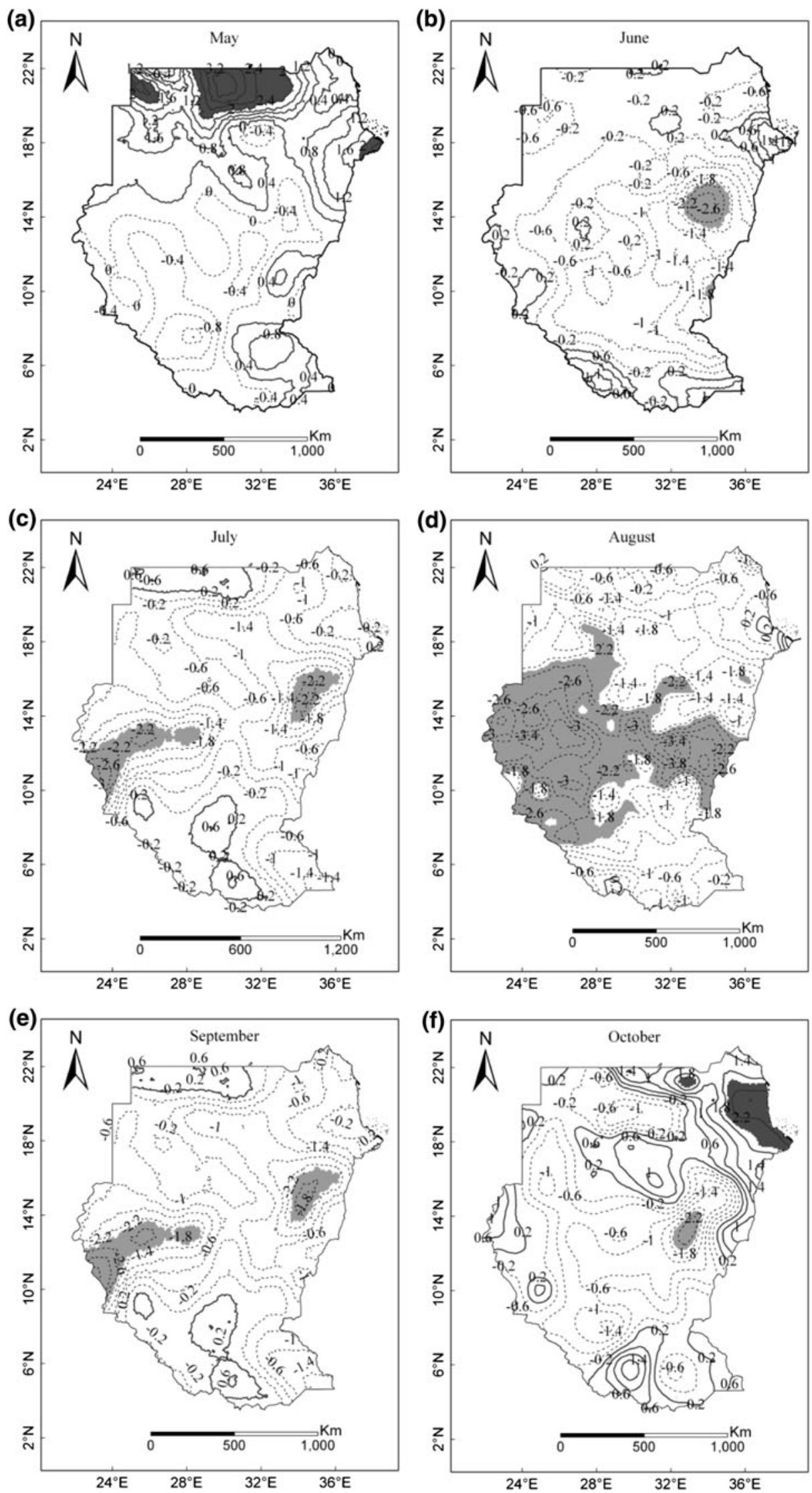
(a)

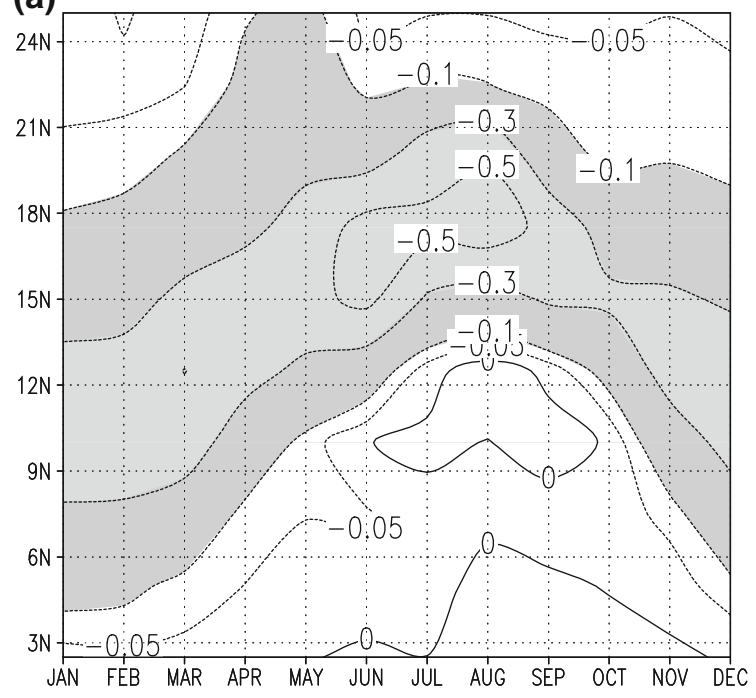

(b)

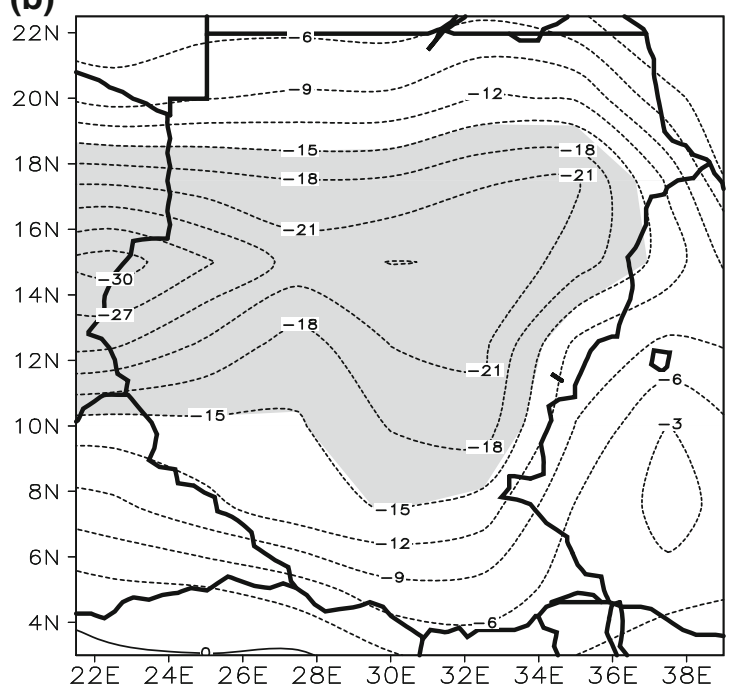

Fig. 8 Anomalies of the whole layer moisture content in Sudan between 1970-2005 and 1948-1969. a Time sections of standardized monthly moisture content anomalies; b geographical distributions of mean moisture content anomalies for summer months (JJA), unit: mm)

1989; Rowell et al. 1995; Long et al. 2000). The objective here is to provide a complementary view to the previous studies by examining the relationship of moisture flux and precipitation trend in the region. Results confirmed that there is a relationship between moisture flux and precipitation variations in Sudan. However, it is by no means to say that the moisture flux is the only factor or more important factor than other factors that have been studied by other authors.

As a whole, the persistent drought over the sub-Saharan Africa (the Sahel region) is accompanied by the weakening summer monsoon and the significant decrease in precipitation might be associated with the weakening monsoons. The northeasterly wind tendency in the Sudan limits the northward propagation of moisture flux to North Sudan. Thus, the precipitation decreases significantly. Quan et al. (2003) found there are corresponding changes in the atmospheric circulation that are associated with the interdecadal changes in summer precipitation over Asia and Africa. Long et al. (2000) also found that the variability of moisture flux is highly related to precipitation in Sudan. Therefore, the weakening African Summer Monsoon caused decreasing northward propagation of moisture flux to North Africa in general and in Sudan in particular. Fontaine et al. (2003) analyzed the atmospheric water and moisture fluxes in West African Monsoon and found that observed Sudan-Sahel rainfall and, in wet (dry) situations, with a clear dominance of westerly (easterly) anomalies in the moisture flux south of $15^{\circ} \mathrm{N}$. Thus, the persistent drought over the sub-Saharan Africa (the Sahel region) might be accompanied by the weakened moisture flux in the region.

\section{Conclusions}

This study analyzed variations in precipitation and the whole layer of moisture flux during 1948-2005 in Sudan with the aim of exploring changes in precipitation and associated atmospheric circulation for the occurrence of precipitation transition in Sudan. Some interesting conclusions are obtained as follows:

1) The annual average precipitation varies greatly in Sudan from almost nil in the north to about $1500 \mathrm{~mm}$ in the extreme Southwest. August is the month with the highest precipitation rates in Sudan; however, the biggest decreasing trend also occurred in this month.

2) Precipitation decreases almost in all months in the rainy season and significantly decreasing trends can be found in rainy season and annually in the central part of Sudan. In August, a large part of central Sudan is dominated by significant deceasing trends.

3) The whole layer of moisture content significantly has decreased in central Sudan in summer since the late $1960 \mathrm{~s}$ which might be one of the causes of the decline in precipitation in central Sudan. Abrupt changes in monthly and annual precipitation have occurred in the late of $1960 \mathrm{~s}$. The moisture flux over Sudan tends to be decreasing after these abrupt changes.

The existing clear relationship between moisture flux and precipitation variations in Sudan means that the changes in moisture flux is one of the main reasons for the spatial and temporal variation of precipitation in the region. This study provides a complementary view to the previous studies that attempted to explain the Sahel persistent 

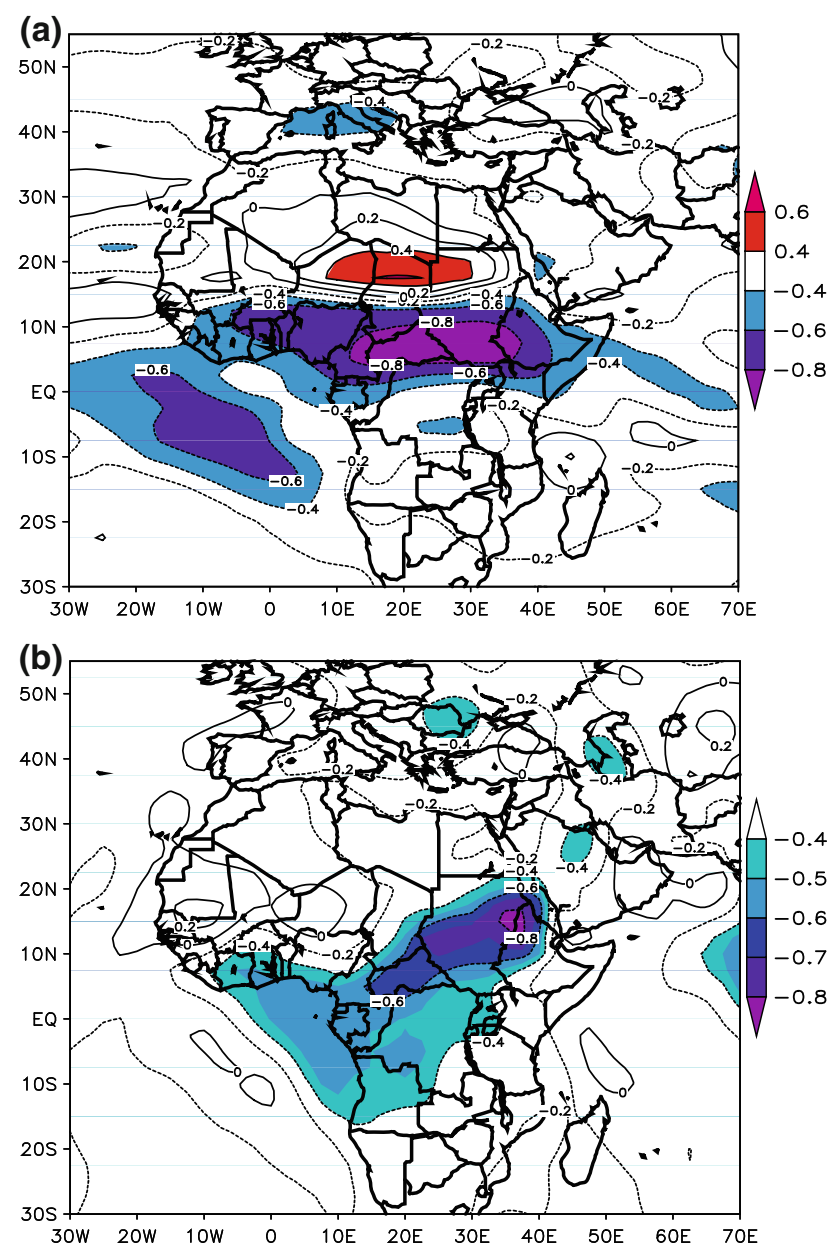

Fig. 9 Spatial distribution of linear trends in whole layer moisture flux in summer (JJA) during 1948-2005 at zonal moisture flux (a) and meridional moisture flux (b) in Africa. The contours indicate the correlation coefficient between time and the moisture flux, for which values large than \pm 0.3 is statistically significant at the $5 \%$ significant level

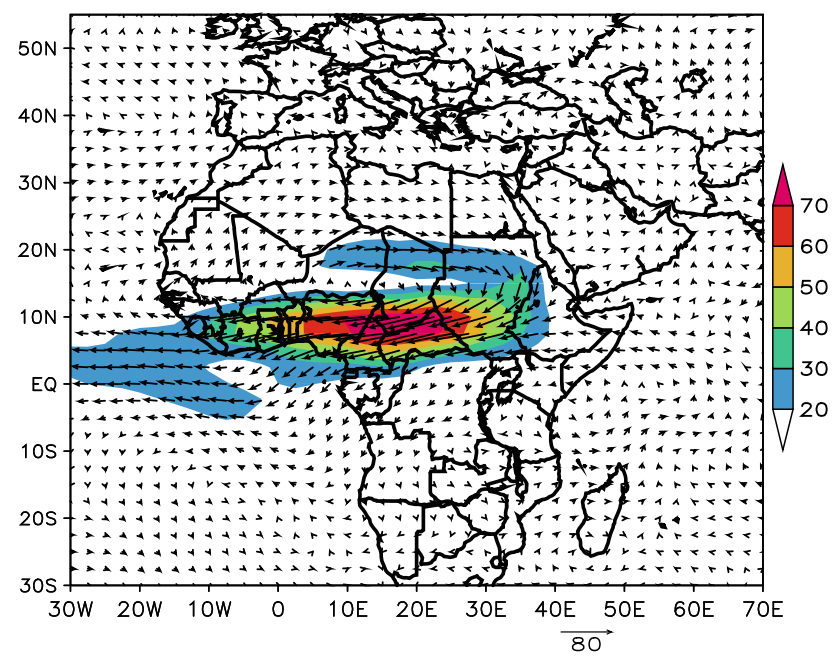

Fig. 10 Spatial distribution of the summer (JJA) atmospheric moisture flux anomalies between 1970-2005 and 1948-1969 (shaded regions indicate $>20 \mathrm{~kg} / \mathrm{m} \mathrm{s}$, unit: $\mathrm{kg} / \mathrm{m} \mathrm{s}$ ) drought in terms of general circulation features, sea surface temperatures, land surface feedback mechanisms, and teleconnected, spatiotemporal rainfall patterns.

Acknowledgments This work is financially supported by The Research Council of Norway (RCN) with project number 171783 (FRIMUF), the Chinese "985 Project" (Grant no. 37000-3171315) and the Program of Introducing Talents of Discipline to Universities- the 111 Project of Hohai University. We would like to thank Prof. Dr Mingyue Chen who provided us the global Precipitation REConstruction (PREC) data, and the data download website can be found in the National Oceanic and Atmospheric Administration (NOAA) Climate Prediction Center: ftp.cpc.ncep.noaa.gov/precip/50yr/.

Open Access This article is distributed under the terms of the Creative Commons Attribution Noncommercial License which permits any noncommercial use, distribution, and reproduction in any medium, provided the original author(s) and source are credited.

\section{References}

Alvi SH (1994) Climate changes, desertification and the Republic of Sudan. GeoJournal 33(4):393-399

Cadet DL, Nnoli NO (1987) Water vapour transport over Africa and the Atlantic Ocean during summer 1979. Quart J Royal Meteorol Soc 113(476):581-602

Camberlin P (1995) June-September rainfall in north-eastern Africa and atmospheric signals over the Tropics: a zonal perspective. Int J Climatol 15:773-783

Chen MY, Xie P, Janowiak JE, Arkin PA (2002) Global land precipiation: a 50-yr monthly analysis based on gauge observations. J Hydrometeorol 3:249-266

Cook KH, Vizy EK (2006) Coupled model simulations of the West African monsoon system: twentieth and twenty first century simulations. J Clim 19:3681-3703

Eltahir EAB (1988) Testing trends in annual rainfall in central and western Sudan. Sudan Eng Soc J 30:37-50

Eltahir EAB (1992) Drought frequency analysis of annual rainfall series in central and western Sudan. J Hydrol Sci 37:185-199

Fontaine B, Roucou P, Trzaska S (2003) Atmospheric water cycle and moisture fluxes in the West African monsoon: mean annual cycles and relationship using NCEP/NCAR reanalysis. Geophys. Res. Lett., 30(3):1117. doi:10.1029/2002GL015834

Gerstengarbe FW, Werner PC (1999) Estimation of the beginning and end of recurrent events within a climate regime. Climate Research 11:97-107

Hulme M (1987) Secular changes in wet season structure in central Sudan. J Arid Environ 13:31-46

Hulme M (1990) The changing rainfall resources of Sudan. Trans Inst Brit Geogr 15(1):21-34

Hulme M, Tosdevin N (1989) The tropical easterly jet and Sudan rainfall: a review. Theor Appl Climatol 39:179-187

Janowiak JE (1988) An investigation of interannual rainfall variability in Africa. J Clim 1:240-255

Janowiak JE, Gruber A, Kondragunta CR et al (1998) A comparison of the NCEP-NCAR reanalysis precipitation and the GPCP raingauge-satellite combined dataset with observational error considerations. J Clim 11:2960-2979

Kendall MG (1975) Rank correlation methods. Griffin, London

Lamb PJ (1978a) Large-scale tropical Atlantic surface circulation patterns associated with Subsaharan weather anomalies. Tellus 30:240-251 
Lamb PJ (1978b) Case studies of tropical Atlantic surface circulation patterns during recent Subsaharan weather anomalies: 1967 and 1968. Mon Wea Rev 106:482-491

Lamb PJ (1982) Persistence of sub-Sahara drought. Nature 299:46-47

Lamb PJ (1983) Sub-Sahara rainfall update for 1982: continued drought. Int J Climatol 3(4):419-422

Long M, Dara E, Sharon EN (2000) Interannual variability in rainfall, water vapor flux, and vertical motion over West Africa. J Clim $13: 3827-3841$

Mann HB (1945) Nonparametric tests against trend. Econometrica 13:245-259

Miao QJ, Xu XD, Zhang SY (2005) Whole layer water vapor budget of Yangtze River valley and moisture flux components transform in the key areas of the plateau. Acta Meteorol Sinica 63:93-99

Nicholson SE (1986) The spatial coherence of African rainfall anomalies: interhemispheric teleconnections. J Climate Appl Meteorol 25(10):1365-1381

Nicholson SE (1989) African drought: characteristics, causal theories and global teleconnections. In: Berger A, Dickinson RE and Kidson JW (eds.) Understanding climate change. American geophysical union geophysical monograph 52:79-100

Nicholson SE, Some B, Kone B (2000) An analysis of recent rainfall conditions in West Africa, including the rainy seasons of the 1997 El Niño and the 1998 La Niña Years. J Clim 13:2628-2640

Osman and Hastenrath (1969) On the synoptic climatology of the summer rainfall over central Sudan. Arch Met Geoph Biokl Ser B 17:297-324

Osman YZ, Shamseldin AY (2002) Qualitative Rainfall prediction models for central and southern Sudan using El Nino Southern Oscillation and Indian sea surface temperature indices. Int. J. Climatology 22:1861-1878

Palmer TN (1986) Influence of the Atlantic, Pacific and Indian Oceans on Sahel rainfall. Nature 322:251-253

Poccard I, Janicot S, Camberlin P (2000) Comparison of rainfall structures between NCEP/NCAR reanalysis and observed data over Tropical Africa. Climate Dyn 16:897-915

Prueger JH, Kustas WP, Hipps LE, Hatfield JL (2004) Aerodynamic parameters and sensible heat flux estimates for a semi-arid ecosystem. J Arid Environ 57:87-100

Quan XW, Diaz HF, Fu CB (2003) Interdecadal change in the AsiaAfrica summer monsoon and its associated changes in global atmospheric circulation. Global Planet Change 37(3-4):171-188

Rowell DP, Folland CK, Maskell K, Ward N (1995) Variability of summer rainfall over tropical North Africa (1906-92): Observations and modelling. Quart J Roy Meteor Soc 121:669-704

Shi N, Chen LW, Xia DD (2002a) A preliminary study on the global land annual precipitation associated with ENSO during 1948-2000. Advan Atmosph Sci 19(6):993-1003
Shi N, Chen LW, Lin ZM (2002b) The relationship between global precipitation and local monsoon precipitation. Meteorolo Sci Technol 30(2):73-79 (in Chinese)

Shi N, Chen LW, Fen GL et al (2004) Climate characters and changes in global precipitation field from 1920 to 2000. Plateau Meteorol 23(4):436-443 (in Chinese)

Sneyers R (1990) On statistical analysis of series of observations. WMO Tech Note, WMO: 143

Trilsbach A, Hulme M (1984) Recent rainfall changes in central Sudan and their physical and human implications. Trans Inst Brit Geogr 9:280-298

Von Storch VH (1995) Misuses of statistical analysis is climate research. In: von Storch VH, Navarra A (eds) Analysis of climate variability: applications of statistical techniques. Springer-Verlag, Berlin, pp 11-26

Walsh RPD, Hulme M, Campbell MD (1988) Recent rainfall changes and their impact on hydrology and water supply in the semi-arid zone of the Sudan. Geog. Jour 154(2):181-198

WMO (1966) Climate change: report of a working group of the commission for climatology. WMO Tech:79

Xu C-Y (2001) Statistical analysis of a conceptual water balance model, methodology and case study. Water Res Manag 15:75-92

Yue S, Wang CY (2002a) Applicability of prewhitening to eliminate the influence of serial correlation on the Mann-Kendall test. Water Resour Res 38(6): 1068

Yue S, Wang CY (2002b) Discussion: a study of variability of annual river flow of the southern African region. Hydrol Sci 47(6):983-989

Yue S, Pilon P, Cavadias G (2002) Power of the Mann-Kendall test and the Spearman's rho test for detecting monotonic trends in hydrological time series. J Hydrol 259:254-271

Zhang Q, Xu C-Y, Zhang Z, Chen YD, Liu C-L (2009) Spatial and temporal variability of precipitation during 1951-2005 over China. Theor Appl Climatol 95:53-68

Zhang Q, Xu C-Y, Tao H, Jiang T, Chen YD (2010a) Climate changes and their impacts on water resources in the arid regions: a case study of the Tarim River basin, China. Stoch Env Res Risk Assess 24:349-358

Zhang ZX, Tao H, Zhang Q et al (2010b) Moisture budget variations in the Yangtze River Basin, China, and possible associations with large-scale circulation. Stoch Environ Res Risk Assess 24(5):579-589

Zhou J, Xue YF, Liu XF (1998) The source/sink distribution of water vapor with its transfer in Asian monsoon region in August, 1994. J Trop Meteorol 14(1):91-96 